\title{
POLÍTICA NACIONAL DE MODERNIZACIÓN DE LA GESTIÓN PÚBLICA Y ROL DE LA CONTRALORÍA GENERAL DE LA REPÚBLICA
}

\section{NATIONAL POLICY OF MODERNIZATION OF THE PUBLIC MANAGEMENT AND ROLE OF THE REPUBLIC GENERAL COMPTROLLER}

\author{
Lázaro Pazos Acosta \\ Magister en Auditoria con mención en Gestión y Control Gubernamental - Universidad Nacional Mayor de San Marcos, Lima, Perú. - \\ Email: lazaropazos@gmail.com (Autor Corresponsal)
}

[Recibido: 18/12/2016 Aceptado: 20/02/2017]

\begin{abstract}
RESUMEN
La investigación permitió determinar que la Política de Modernización de la Gestión Pública (PNMGP), no se aplica en las actividades inherentes de la Contraloría General de la República (CGR), no obstante que es de cumplimiento obligatorio por todas las organizaciones del Sector Público para lograr entre otros, acercar el Estado a los ciudadanos. A partir de dicho objetivo, se realizó un análisis descriptivo sobre la relación entre las variables y se utilizó el software SPSS-21 para la prueba estadística del chi cuadrado. En tal sentido, se obtuvieron como principales resultados que no existe una relación entre la PNMGP y el modelo de gestión para la lucha contra la corrupción por parte de la CGR. En este mismo orden y dirección se demuestra que la Contraloría General de República viene actuando con normativa interna no actualizada a la PNMGP que no rinden los frutos para reducir la corrupción, pese que desde el 2009 al 2016 el presupuesto para resultados ha sido incrementado notablemente no logra reducir las deficiencias en las prestaciones de los servicios públicos (salud, educación, transporte, vivienda, entre otras), las cuales terminan incidiendo negativamente en la percepción ciudadana sobre la el desempeño del Estado, debido a que el control gubernamental es ineficiente en menoscabo de los grandes objetivos del milenio que busca poner fin a la pobreza, hambre cero, salud y bienestar, educación de calidad, igualdad de género, agua limpia y saneamiento, entre otros.
\end{abstract}

\section{PALABRAS CLAVE}

Política nacional, modernización, gestión pública, contraloría.

\begin{abstract}
The research made possible to determine that the Public Management Modernization Policy (PNMGP) does not apply to the inherent activities of the Republic General Comptroller (CGR), although it is mandatory for all Public-Sector organizations- among other things-to bring the State closer to the citizens. From this objective, a descriptive analysis was performed on the relationship between the variables, and the SPSS-21 software was used for the chi-square statistical test. In this sense, the main results obtained were that there is no relationship between the PNMGP and the management model for the fight against corruption by the CGR. In this same order and direction it is shown that the Republic General Comptroller has been acting with internal regulations not updated to the PNMGP that do not yield the fruits to reduce corruption, although from 2009 to 2016 the budget for results has been increased notably, it does not manage to reduce deficiencies in the provision of public services (Health, education, transportation, housing, among others), which end up having a negative impact on the citizen's perception of the performance of the State, since government control is ineffective in terms of impairment of the great millennium goals that seeks to end poverty, zero hunger, health and welfare, quality education, gender equality, clean water and sanitation, among others.
\end{abstract}

\section{KEYWORDS}

National policy, modernization, public management, comptroller.

Como Citar: Pazos, L. (2017). Análisis tributario de las comisiones por servicios de los agentes intermediarios textiles. Quipukamayoc 25(48), 61-69. doi: http://dx.doi.org/10.15381/quipu.v25i48.13993 


\section{INTRODUCCIÓN}

El presente artículo relaciona la $\mathrm{PN}$ MGP y el rol de la CGR, por el cual se busca potenciar el control gubernamental para certificar el buen uso de los recursos públicos, crear un clima de confianza de la ciudadanía con las organizaciones del Estado. Es necesario indicar que la CGR es una Organización Constitucionalmente $\mathrm{Au}$ tónoma que no depende de ninguno de los poderes del Estado, que señala la Constitución Política del Perú de 1993, a efectos que su accionar este orientada para la salvaguarda del estado de derecho.

Realizadas las consideraciones anteriores, se formula la siguiente interrogante: ¿Se encuentra relacionada la Política Nacional de Modernización de la Gestión Pública con el rol de la Contraloría General de la República?

En ese orden de ideas, la hipótesis que responde a la pregunta es: La Política Nacional de Modernización de la Gestión Pública, no se encuentra relacionada con el rol de la Gestión de la Contraloría General de la República.

En este propósito, se expone los fundamentos teóricos de Douglass North. Asimismo, se analiza la Constitución Política del Perú, la Ley de Creación del Sistema Nacional de Control, y normas conexas sobre el accionar de la CGR.

De igual forma, el estudio recurre al enfoque mixto. En ese mismo sentido, la principal limitación de la investigación es la de no haber tenido información de primera mano sobre la ejecución presupuestaria del ente de control y; para la facilitar la comprensión del estudio, el contenido se ha desagregado en cinco (5) catego- rías. La primera comprende la fundamentación teórica. La segunda abarca del marco legal. La tercera se plantea la metodología. La cuarta abarca los resultados. En la quinta se plantea la discusión. Adicionalmente, se presentan las conclusiones, terminando con las referencias bibliográficas.

North (1993) señala que el papel del Estado desde el punto de vista institucionalismo el objetivo es determinar la eficiencia de las reglas de juego que ha creado. Las reglas creadas por el Estado deben buscar la eficiencia productiva, o eficiencia asignativa, que mide la cantidad de producto que se obtiene según la asignación de recursos que se haya hecho. Con este criterio, el Estado debe crear instituciones que fomenten, impulsen y expandan la producción de la forma más eficaz.

Las instituciones son las reglas del juego en una sociedad o, más formalmente, son las limitaciones ideadas por el hombre que dan forma a la interacción humana. Por consiguiente, estructuran incentivos en el intercambio humano, sea político, social o económico. El cambio institucional conforma el modo en que las sociedades evolucionan al largo del tiempo, por lo cual es la clave para entender el cambio histórico (North,1993, p. 13).

Además nos indica que Las instituciones incluyen todo tipo de limitación que los humanos crean para dar forma a la interacción humana. ¿Son formales o informales las instituciones? Pueden ser una u otra cosa, ... (...) por ejemplo, normas que idean los humanos, como en limitaciones informales, tales como acuerdo y códigos de conducta. Las instituciones pueden ser creadas como lo son las constituciones políticas de los Estados; o bien evolucionar simplemente a lo del tiempo, cómo evoluciona el derecho consuetudinario (North, 1993, pág. 14).

Por otro lado el cumplimiento obligatorio rara vez es una y otra cosa, en tanto que la estructura de los mecanismos de cumplimiento y la frecuencia y la severidad de la imperfección desempeñan una función importante en los costos de transacción y en las formas que adoptan los contratos. Hay dos razones que explican por qué el cumplimiento obligatorio es típicamente imperfecto. La primera que exploran los costos de medir los márgenes múltiples que constituyen el desempeño del contrato. La segunda se apoya en el hecho de que el cumplimiento obligatorio corre a cargo de agentes cuyas propias funciones de utilidad influyen en los resultados (North, 1993, pág.75).

La Figura 1 sustenta el Marco Institucional del Sistema Nacional de Control y de la Controlaría General de la Republica sobre la base del enfoque institucional de North a afectos de comprender el alcance de las reglas formales, las reglas informales y las organizaciones.

El primer componente está relacionado con las Instituciones, que pueden ser reglas formales e informales. Las reglas formales son las normas, leyes, Decretos Legislativos, Directivas, etc. que orientan y rigen la marcha de las organizaciones del Estado, las cuales deben ser claras y fáciles para arribar a una interpretación auténtica que facilite la convivencia e interacción entre las organizaciones. Las reglas 


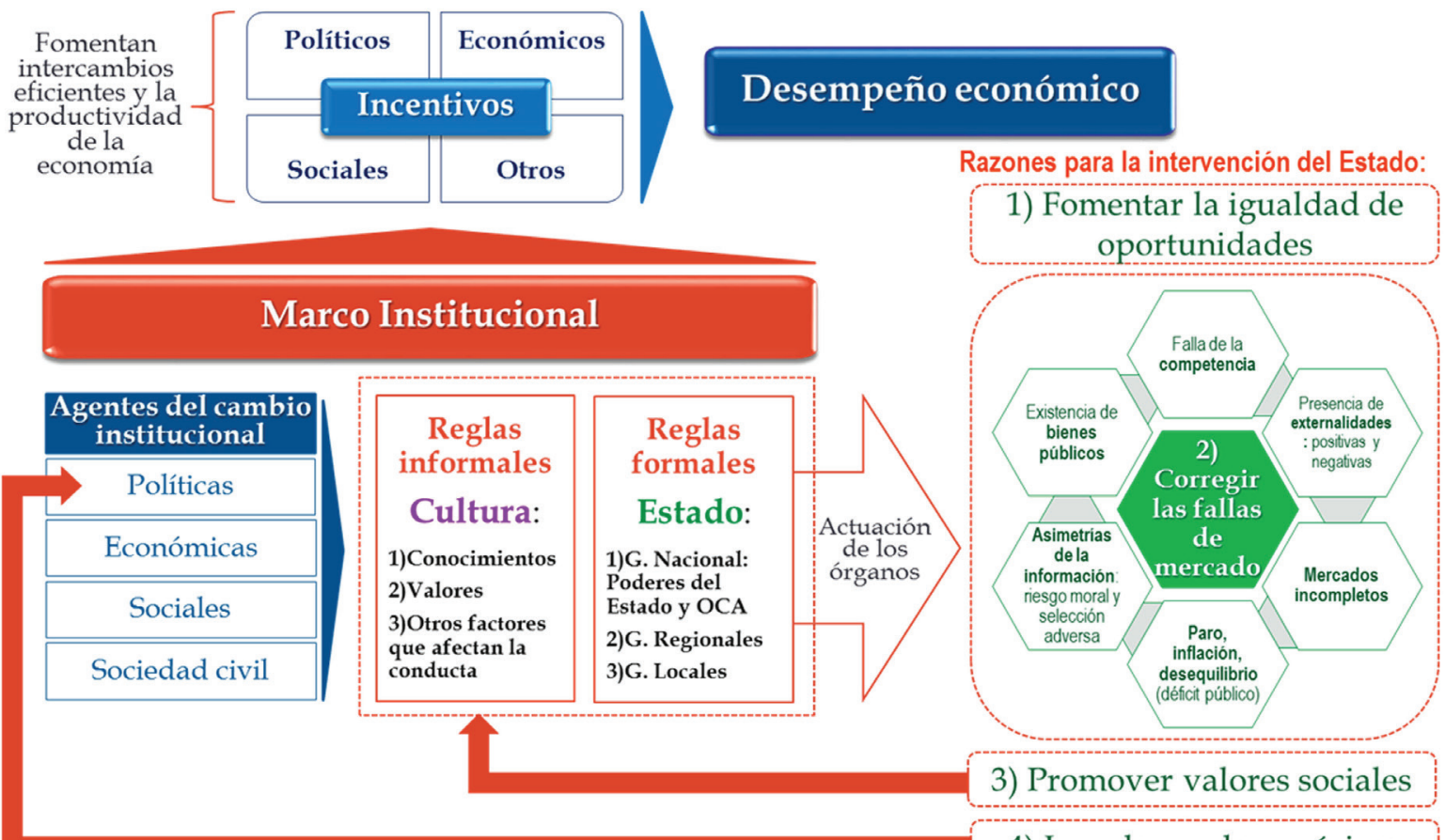

4) Impulsar valores cívicos

Figura 1. Enfoque Institucional del Sistema Nacional de Control y de la CGR sobre la base de la teoría de las Instituciones de Douglass North Fuente: Rodríguez (2017). Créditos del sistema financiero al sector privado y regulación del mercado de créditos en Perú

informales son las costumbres, cultura, valores.

Pues bien, en nuestro país las Instituciones Formales tienen su base normativa en la Constitución Política, norma que distribuye o equilibra los poderes del Estado, y designa los organismos constitucionalmente autónomos, entre los cuales se encuentra la CGR que es formalizada con la Ley No 27785 Ley Orgánica del Sistema Nacional de Control y de la Contraloría General de la República, cuyo objetivo es la de propender al apropiado, oportuno y efectivo ejercicio del control gubernamental, para prevenir y verificar, mediante la aplicación de principios, sistemas y procedimientos técnicos, la correcta, eficiente y trans- parente utilización y gestión de los recursos y bienes del Estado.

En referencia a la clasificación anterior se tiene las Reglas Informales, que devienen de los usos y costumbres, no están establecidas en ninguna ley pero por costumbre el servidor público y la ciudadanía lo absorbe como ley formal, (se cumplen por el derecho consuetudinario).

Como segundo componente se tiene a las Organizaciones, que están constituidos por grupos de individuos que se vinculan entre sí para alcanzar un fin o propósito en particular, para ilustrar pueden ser las iglesias, clubes, asociaciones deportivas, partidos políticos, Universidades, Institutos, co- legios profesionales, etc. Las Organizaciones se basan y se formalizan bajo una estructura orgánica y reglamento, por los cuales aseguran el fortalecimiento y cumplimiento de las reglas formales y de esta manera minimizar las reglas que se emplean por usos y costumbres.

Asimismo, North (1993) refiere que el cumplimiento obligatorio significa el desarrollo del Estado como una fuerza coercitiva capaz de monitorear derechos de propiedad y hacer cumplir contratos.

Es decir, que es el mecanismo o el imperio coercitivo que tiene el Estado para hacer cumplir las normas, co- 
menzado por la Constitución Política del Estado, leyes, derechos de propiedad, contratos, etc.

\section{Marco legal}

Constitución Política del Perú de 1993. Artículo 82.- La Contraloría General de la República La Contraloría General de la República es una entidad descentralizada de Derecho Público que goza de autonomía conforme a su ley orgánica. Es el órgano superior del Sistema Nacional de Control. Supervisa la legalidad de la ejecución del Presupuesto del Estado, de las operaciones de la deuda pública y de los actos de las instituciones sujetas a control. (...).

Decreto Supremo $N^{\circ} 304-2012-E F$, que aprueba el Texto Único de la Ley $\mathrm{N}^{\circ}$ 28411, Ley General del Sistema Nacional de Presupuesto. Artículo 31.1: "La Contraloría General de la Republica y los Órganos de Control Interno de las Entidades supervisan la legalidad de la ejecución del presupuesto público comprendiendo la correcta gestión y utilización de los recursos y bienes del Estado, según lo estipulado en la Ley Orgánica del Sistema Nacional de Control de la Contraloría General de la República - Ley N²7785”.

Decreto Supremo $N^{\circ}$ 043-2006-PCM Lineamiento para la elaboración y aprobación del Reglamento de Organización y Funciones - ROF por parte de las entidades de la Administración Pública.

Ley $N^{o}$ 27785, Ley Orgánica del Sistema Nacional de Control y de la Contraloría General de la República y sus modificatorias, cuyo objeto de la Ley es propender al apropiado, oportuno y efectivo ejercicio del control gubernamental, para prevenir y verificar, mediante la aplicación de principios, sistemas y procedimientos técnicos, la correcta, eficiente y transparente utilización y gestión de los recursos y bienes del Estado, el desarrollo honesto y probo de las funciones y actos de las autoridades, funcionarios y servidores públicos, así como el cumplimiento de metas y resultados obtenidos por las instituciones sujetas a control, con la finalidad de contribuir y orientar el mejoramiento de sus actividades y servicios en beneficio de la Nación.

Resolución de Contraloría No 4452014-CG, que aprueba la Directiva No 005-2014-CG/AFIN denominada "Auditoría Financiera Gubernamental" y El "Manual de Auditoría Financiera Gubernamental”, como el nuevo instrumento de uso obligatorio en las auditorías financieras del sector público que se ejecuten por el Sistema Nacional de Control.

El nuevo manual tiene como atributo de ser una fuente de consulta para las auditorías de carácter financiero, si bien es cierto se afirma que, en las auditorías financieras del sector público, se prioriza la auditoría a los estados presupuestarios y su efecto en los estados financieros a través del paralelismo contable, que deben ser planeados y ejecutados en forma paralela. Esta afirmación desencanta en que no existe el puente para unir una auditoría con la otra, es decir, no existe cedulas matrices, una guía o un algoritmo que relacione la auditoría Presupuestaria con la Financiera.

Plan Estratégico Institucional, con la Resolución de Contraloría $\mathrm{N}^{\circ}$ 2832015-CG, se aprueba el Plan Estratégico Institucional para el periodo 2015 - 2017, en la parte de los considerandos no hace mención a la Polí- tica de Modernización de la Gestión Pública. En dicho plan, dentro de la perspectiva de procesos, se enuncia cinco objetivos estratégicos, de los cuales uno está inmerso en la presente investigación $y$, que a la letra dice: Reforzar el modelo de gestión para la lucha contra la corrupción y mejora de la eficiencia.

Decreto Supremo $N^{\circ} 004-2013-P C M$ "Aprueba la Política Nacional de Modernización de la Gestión Pública”. Es el instrumento orientador de la modernización de la gestión pública en el Perú, que establecerá la visión, los principios y lineamientos para una actuación coherente y eficaz del sector público, al servicio de los ciudadanos y el desarrollo del país, por lo cual se busca que las organizaciones realicen cambios administrativos y de gestión para afirmar las políticas de Estado y de Gobierno mediante la gestión por resultados del presupuesto asignado.

Dicha norma tiene el ámbito de aplicación en: 1) El Poder Ejecutivo, incluyendo Ministerios y Organismos Públicos, 2) Los Gobiernos Regionales, 3) Los Gobiernos Locales, 4) Los Organismos a los que la Constitución Política del Perú y las leyes confieren autonomía y, 5) Las mancomunidades municipales.

Como puede observarse esta norma tiene alcance para la Contraloría General de la República que es un Organismo Constitucionalmente Autónomo. A continuación se mencionan aspectos relacionados con el presente artículo:

Perú tiene uno de los Estados más disfuncionales de América Latina. Muchas instituciones estatales no funcionan, y en algunas zonas, ni siquiera existen. En muchas partes del interior, 
los servicios públicos (educación, salud, agua potable, infraestructura) no llegan, y si llegan, están plagados por la corrupción y la ineficiencia. Los gobiernos locales y regionales carecen de un mínimo de capacidad administrativa. Y la seguridad y la justicia funciones básicas del Estado- no son ni mínimamente garantizadas.

Deficiente diseño de la estructura de organización y funciones

En muchas entidades, su estructura de organización y funciones no necesariamente viene siendo congruente con las funciones que deben cumplir ni tampoco con los objetivos que pueda haberse fijado como resultado de sus procesos de planeamiento estratégico-operativo y de su presupuestación. Ello puede deberse a que las organizaciones fueron diseñadas bajo un modelo de gestión funcional, con estructuras jerárquicas, estamentales y sin claridad en los procesos que deben realizar para entregar los bienes y servicios públicos de su responsabilidad con la calidad y pertinencia requeridos. Además, los lineamientos y los modelos vigentes para la formulación de documentos de gestión -ROF, CAP, etc.- imponen normas uniformes de organización para la gran diversidad de entidades existentes.

\section{Presupuesto para resultados}

Un Estado moderno al servicio del ciudadano, además de objetivos claros, requiere que sus presupuestos sean asignados también con orientación a resultados, es decir, en función a los productos que los ciudadanos esperan recibir para satisfacer sus demandas. Sobre todo, considerando que los recursos son escasos, lo cual obliga a priorizar. En ese proceso la transparencia y rendición de cuentas son sumamente importantes en los procesos de asignación y evaluación del destino de los recursos.

\section{MATERIAL Y MÉTODOS}

El estudio correspondió a un diseño no experimental debido que no se ha propiciado situación alguna para intervenir en la manipulación de la variable independiente, ya que ésta se encuentra establecida por el gobierno nacional. La investigación fue descriptiva en razón que se analizaron las dos variables de estudio. Teniendo un enfoque fue mixto, esto es cuantitativo por ser probatorio mediante el software estadístico y cualitativo por el análisis realizado a las actividades del Órgano Superior de Control.

La unidad de análisis fueron los auditores del Sistema Nacional de Control. Realizando un tratamiento de datos y análisis de la información de la siguiente manera:

- Análisis descriptivo de encuestas a auditores gubernamentales. A partir de los datos obtenidos de un cuestionario de preguntas cerradas, permitió determinar si la Política Nacional de Modernización de la Gestión Pública está asociada con el rol de la Contraloría General de la República.

- Prueba de Hipótesis mediante chi-cuadrado. La hipótesis de investigación por su naturaleza está asociada a la prueba del ChiCuadrado. Como parte del procedimiento se elaboró manualmente una tabla de contingencias a efectos de validar los resultados que arrojarían el programa SPSS- 21. La significación de Chi-cuadrado ( $\mathrm{p}$-value) es una medida más exacta que el propio valor de Chi y por ello se empleó este dato para comprobar si el resultado es significativo o no. Por lo que:

Si $\mathrm{p}<0,05$ el resultado es significativo, es decir, rechazamos la hipótesis nula de independencia y por lo tanto concluimos que ambas variables estudiadas son dependientes, existe una relación entre ellas. Esto significa que existe menos de un 5\% de probabilidad de que la hipótesis nula sea cierta en nuestra población.

Si $\mathrm{p}>0,05$ el resultado no es significativo, esto es, aceptamos la hipótesis nula de independencia y por lo tanto concluimos que ambas variables estudiadas son independientes, no existe una relación entre ellas. Esto significa que existe más de un 5\% de probabilidad de que la hipótesis nula sea cierta en nuestra población y lo consideramos suficiente para aceptar.

Análisis del organigrama y presupuesto de la CGR

Sin perjuicio de la prueba de chicuadrado, se realizó el análisis al organigrama de la organización, para tal efecto se efectúo el examen al Decreto Supremo No 043-2006-PCM "Lineamiento para la elaboración y aprobación del Reglamento de Organización y Funciones - ROF por parte de las entidades de la Administración Pública”, básicamente al acápite relacionado con los órganos de asesoramiento, que le corresponde a Planificación, Presupuesto y Asesoría Jurídica. Mediante el organigrama se pudo inferir que los órganos estructurados de la entidad no fueron diseñados bajo un modelo de gestión funcional y con claridad en los procesos que realiza, por lo tanto, repercute en la ejecución de los gastos que no se realizó bajo la lógica del Presupuesto para Resultados. 


\section{RESULTADOS}

Hipótesis: La Política Nacional de Modernización de la Gestión Pública, no se encuentra relacionada con el rol de la Gestión de la Contraloría General de la República.

De ahí que la Hipótesis fue evaluada, analizada e interpretada tomando en cuenta las siguientes variables:

\section{Tabla 1.}

Aplicación de la Política de Modernización de la Gestión Pública en la CGR Fuente: Elaboración propia

\begin{tabular}{|c|c|c|c|c|c|}
\hline & \multicolumn{5}{|c|}{ Variable Dependiente } \\
\hline & & \multicolumn{3}{|c|}{ Rol de la Gestión de la CGR } & TOTAL \\
\hline & & $\mathrm{Si}$ & No & No sabe & \\
\hline \multirow{2}{*}{$\begin{array}{l}\text { Variable Indepen- } \\
\text { diente }\end{array}$} & $\mathrm{Si}$ & $\mathrm{N} / \mathrm{A}$ & 0 & 0 & 20 \\
\hline & No & 0 & 5 & 0 & 5 \\
\hline \multirow{3}{*}{$\begin{array}{l}\text { Política de } \\
\text { Modernización de la } \\
\text { Gestión Pública }\end{array}$} & No sabe & & & & \\
\hline & $\mathrm{N} / \mathrm{A}$ & 0 & 0 & 0 & 0 \\
\hline & TOTAL & 20 & 5 & 0 & 25 \\
\hline
\end{tabular}

Tabla 2.

Pruebas de chi-cuadrado

Fuente: Elaboración propia

a. 3 casillas (75,0\%) tienen una frecuencia esperada inferior a 5. La frecuencia mínima esperada es 1,00. b. Calculado sólo para una tabla de $2 \times 2$.

\begin{tabular}{|c|c|c|c|c|c|}
\hline & Valor & gl & $\begin{array}{l}\text { Sig. asintótica } \\
\text { (bilateral) }\end{array}$ & $\begin{array}{c}\text { Sig. } \\
\text { exacta } \\
\text { (bilateral) }\end{array}$ & $\begin{array}{l}\text { Sig. exacta } \\
\text { (unilate- } \\
\text { ral) }\end{array}$ \\
\hline $\begin{array}{l}\text { Chi-cuadrado } \\
\text { de Pearson }\end{array}$ & $25000^{\mathrm{a}}$ & 1 & 0,000 & & \\
\hline $\begin{array}{l}\text { Corrección por } \\
\text { continuidad }^{\mathrm{b}}\end{array}$ & 19141 & 1 & 0,000 & & \\
\hline $\begin{array}{l}\text { Razón de vero- } \\
\text { similitudes }\end{array}$ & 25020 & 1 & 0,000 & & \\
\hline $\begin{array}{l}\text { Estadístico } \\
\text { exacto de Fisher }\end{array}$ & & & & 0,000 & 0,000 \\
\hline $\begin{array}{l}\text { Asociación } \\
\text { lineal por lineal }\end{array}$ & 24000 & 1 & 0,000 & & \\
\hline $\begin{array}{l}\mathrm{N} \text { de casos } \\
\text { válidos }\end{array}$ & 25 & & & & \\
\hline
\end{tabular}

nización de la Gestión Pública no se aplica al rol de Gestión de la Contraloría General de la República.

Análisis de las encuestas realizadas a los auditores gubernamentales sobre las variables del estudio

Tal como se puede apreciar en la siguiente tabla, el resultado de la encuesta realizada a veinte y cinco (25) auditores gubernamentales puso en evidencia que el Órgano Superior de Control Gubernamental (CGR), es ajeno al cumplimiento de la Política Nacional de Modernización de la Gestión Pública. Veinte (20) auditores respondieron positivamente que la PNMGP está en contradicción con la gestión de la CGR; por las "Constantes modificaciones del CAP", "Deficiente diseño de la estructura de organización y funciones", "Ausencia de un sistema eficiente de Planeamiento" y su normativa no está actualizada a la PNMGP. Asimismo, cinco (5) auditores respondieron que no existe contradicción entre la PNMGP y el rol de la CGR.

Con la referencia a lo anterior, el resultado de tabla de contingencia permitió sustentar numéricamente la vista de variables y, la vista de datos del software SPSS- 21. Como podemos observar y concluir, lo analizado en la tabla de contingencia: las variables de estudio PNMGP y el rol de la CGR son datos concretos y válidos de los 25 auditores encuestados. Con esta información se puede concluir que la PNMGP es independiente del rol de la CGR

Análisis de la significancia mediante el Chi-Cuadrado

Para validar los resultados, hay que fijarse en el valor "a”, que se encuen- 
tra al final de la siguiente tabla. En tal sentido, para este estudio se tiene 3 casillas con un resultado del $75 \%$ y tiene una frecuencia esperada inferior a 5 se concluye la independencia de las variables.

En virtud que $\mathrm{p}>0,05$, el nivel significación arroja que X1 no está relacionada con Y1, lo cual permite aseverar que la Política Nacional de Modernización de la Gestión Pública no se aplica al rol de Gestión de la Contraloría General de la República.

En razón de ello el resultado no es significativo, es decir, aceptamos la hipótesis nula de independencia, y por lo tanto, ambas variables estudiadas son independientes, no existe una relación entre ellas. Esto significa que existe más de un $5 \%$ de probabilidad de que la hipótesis nula sea cierta en nuestra población y lo consideramos

Tabla 3.

Nivel de significancia y decisión

Fuente: Elaboración propia

\begin{tabular}{ll}
\hline Nivel de significancia & $\alpha=0,05$ \\
\hline Valor significativo (p-value) & $\mathrm{P}=0,000$ \\
\hline Decisión & $\mathrm{P}<\alpha$ \\
& $\mathrm{P}=0.000<\alpha=0,05$ \\
\hline
\end{tabular}

suficiente para su aceptación. Por lo que, el análisis de significancia se puede apreciar en la Tabla 3.

Por tanto, la prueba de hipótesis del presente estudio se determinó que el valor observado de una variable no depende del valor observado de la otra variable.

Análisis del organigrama de la CGR Como se aprecia en el organigrama de la CGR, la Gerencia de Central de Planeamiento se encuentra bajo el mando de la Gerencia Central de Administración (OGA), es decir, no se le ha dado la categoría de órgano de asesoramiento e independencia para cumplir la programación y formulación del presupuesto, lo que origina que el órgano superior disponga modificaciones al presupuesto institucional rompiendo la cadena de la programación, formulación y ejecución de las actividades y metas aprobadas por la Ley de Presupuesto.

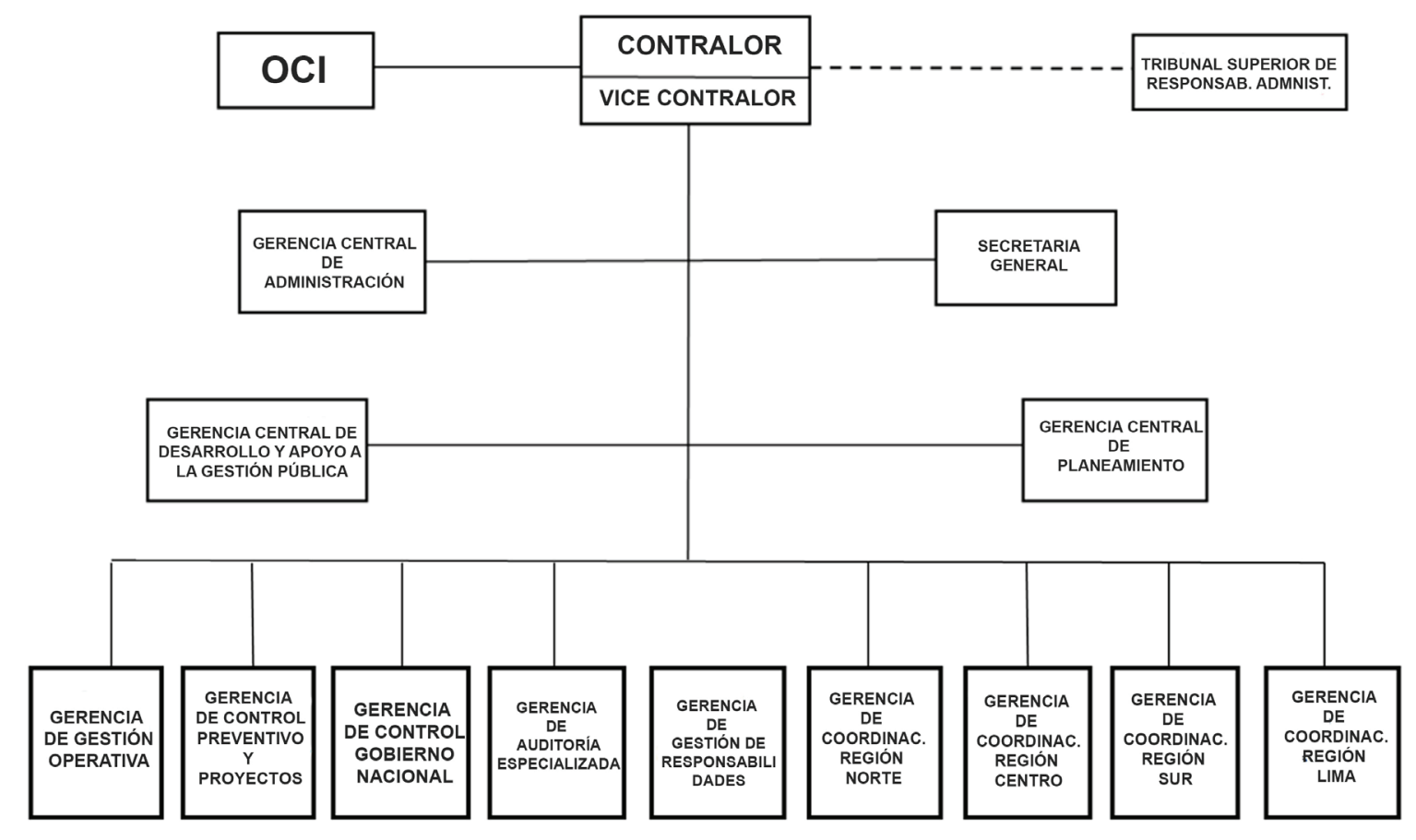

Figura 2. Organigrama de la CGR

Fuente: Elaboración propia 
Tabla 4.

Asignaciones presupuestales a la CGR

Fuente: Memoria de la CGR 2009 - 2015 / Web del MEF - pagina amigable

\begin{tabular}{|c|c|c|c|}
\hline PIM & Ejercicio & $\begin{array}{l}\text { Incremento } \\
\text { presupuestal }\end{array}$ & $\begin{array}{l}\text { Incremento } \\
\text { Porcentual }\end{array}$ \\
\hline & 2009 & 172882223 & 0 \\
\hline Financiamien- & 2010 & 226719131 & 1,31 \\
\hline \multirow{4}{*}{$\begin{array}{l}\text { to: Recursos Ordinarios, } \\
\text { Recursos Directamente Re- } \\
\text { caudados, Recursos por Ope- } \\
\text { raciones Oficiales de Crédito y, }\end{array}$} & 2011 & 302416232 & 1,74 \\
\hline & 2012 & 352924494 & 2,04 \\
\hline & 2013 & 349826950 & 2,02 \\
\hline & 2014 & 371324587 & 2,14 \\
\hline \multirow{2}{*}{ Donaciones y Transferencias. } & 2015 & 470518573 & 2,72 \\
\hline & 2016 & 511393528 & 2,95 \\
\hline \multicolumn{2}{|l|}{ Total: S/. } & 2758005718 & 14,92 \\
\hline
\end{tabular}

Análisis de las Asignaciones presupuestarias a la CGR

En la Tabla 4 se muestra el comportamiento de las asignaciones presupuestales que la CGR de los últimos ocho (8) años. Presupuesto para financiar las actividades de fiscalización de los recursos del Estado. Se observa que la CGR ha tenido un incremento porcentual del $14.92 \%$ en el referido periodo. La totalidad de los presupuestos asignados asciende a S/ $2,758,005,718$ cuyo objetivo es cumplir con las actividades de supervisión al presupuesto de la República; sin embargo, la realidad dice todo lo contrario los recursos se han utilizado en una metodología de auditoría que no es la que dispone la Carta Magna y la propia Ley de Creación de la CGR, por lo tanto, el gasto presupuestal no ha sido bajo la lógica Presupuesto para Resultados.

\section{DISCUSIÓN}

La Constitución Política del Perú es muy breve al señalar el rol de la CGR se encuentra en el capítulo IV del Régimen Tributario y Presupuestal. De ahí que la CGR potenciaría la gestión de control, si toma en consideración la norma de La Política Nacional de Modernización de la Gestión Pública. El órgano superior de control tiene el reto de hacer cumplir las normas formales en concordancia con la Constitución Política del Perú.

La CGR ha recibido asignaciones presupuestales en los últimos ocho años por un importe total de $S / 2758$ 005,718 para supervisar los objetivos y metas presupuestarias, sin embargo, este monto ha sido utilizado en el control financiero (auditoría financiera) contrario a lo que dispone la Constitución Política del Perú y la propia ley de creación del Sistema Nacional de Control y de la Contraloría General de la República, que debe supervisar el presupuesto del Estado.

Existe una vinculación muy fuerte entre los resultados del estudio con las bases teóricas de la investigación; tal como señala la teoría de North respecto a la debilidad institucional. En efecto, la CGR en una organización informal en las actividades de control, que devienen de los usos y costumbres (accionar por el derecho consuetudinario). No obstante que la Constitución Política del Perú en el Art. 82 establece que el control al régimen económico y financiero del Estado debe ser con la supervisión al presupuesto de la nación.

Además, los hechos de usos y costumbres tradicionales tienen tal arraigo que vienen involucionado en perjuicio del control gubernamental, tal como se evidencia con la Resolución de Contraloría No 445-2014-CG, que aprueba la Directiva No 005-2014CG/AFIN denominada "Auditoría Financiera Gubernamental" y el "Manual de Auditoría Financiera Gubernamental", como nuevo instrumento de uso obligatorio en las auditorías financieras del sector público que se ejecuten por el Sistema Nacional de Control. El manual establece disposiciones y los criterios técnicos aplicables a la auditoría financiera, mas no para la auditoría al presupuesto.

Por otro lado, la CGR con el nuevo manual de Auditoría Financiera Gubernamental no está diseñada para la lucha contra la corrupción o en su defecto invita realizar actos de corrupción, utilizar dinero de las arcas del erario nacional para realizar actos reñidos a la ley, que los gestores de turno realicen actos discrecionales en perjuicio de la ciudadanía y lo más delicado aun, poniendo en peligro el estado de derecho del país.

Sin perjuicio de lo antes señalado en los párrafos precedentes, la agenda de investigación deja para un futuro muy corto, investigaciones orientadas a construir un nuevo modelo de auditoría para las organizaciones del Estado que se complemente con la auditoría financiera gubernamental, como entrar a la etapa de adecuación a la Política de Modernización de la Gestión Pública. En ese sentido, se debería tratar de responder las siguientes interrogantes: ¿Es imperante contar con un nuevo modelo de auditoría gubernamental?, ¿La aplicación de la 
Política Nacional de Modernización de la Gestión del Estado, rompería los esquemas del modelo burocrático de Max Weber que se utiliza hoy en día en el Estado?

Finalmente, cabe agregar que la principal limitante del estudio fue la disponibilidad del acervo documentario de los resultados (informes) de las auditorías realizadas por el SNC a partir del 2009 al 2016. A efectos de comprobar la hipótesis se recurrió a la interpretación de los documentos técnicos de gestión de la CGR que deberían estar alineados con la normativa de La Política Nacional de Modernización de la Gestión Pública.

Los resultados de la investigación permitieron evidenciar que la CGR no ha realizado algún acto de transición para cumplir con la Política Nacional de la Modernización de la Gestión Pública, Como corolario se puede afirmar por más personal o presupuesto que se le dote a dicho órgano los resultados serán los mismos por ser una organización que no cumple con la normatividad del Sector Publico, aun mas con la misión encomendada que a letra dice: "Promover el desarrollo de una gestión eficaz y moderna de los recursos públicos en beneficio de todos los peruanos".

El Portal de Transparencia de la CGR permite señalar que poco o nada han avanzado en cumplir con la Política Nacional de Modernización de la Gestión Pública, que está estructurado en cinco (5) pilares centrales, el primer pilar: Políticas Públicas, Planes Estratégicos y Operativos, segundo pilar: Presupuesto para Resultados, tercer pilar, Gestión por Procesos, simplificación administrativa y organización institucional, cuarto pilar: Servicios Civil Meritocrática y el quinto pilar: Sistemas de Información, Seguimiento, Monitoreo, Evaluación y Gestión del Conocimiento (todo lo anterior para arribar a la Gestión del Cambio). Asimismo, tienes tres (3) ejes transversales, el primero: Gobierno Abierto, el segundo: Gobierno Electrónico y tercero: Articulación InterInstitucional. Otra prueba es que por los usos y costumbres, la organización viene involucionado negativamente tal como se evidencia con el nuevo "Manual de Auditoría Financiera Gubernamental", como nuevo instrumento de uso obligatorio en las auditorías en el Sector Público.

En el diseño de la estructura orgánica de la CGR no prevalece el principio de especialidad, por el cual debe integrarse las funciones y competencias afines. Al respecto, la especialidad puede darse: En razón de la función a cumplirse. Así, las funciones o tareas similares no deben ser ejercidas por más de un órgano al interior de la entidad. Asimismo, vulnera la Legalidad de las funciones como se observa en el organigrama que la Gerencia de Planeamiento depende de la Gerencia Central de Administración. Por lo tanto, las normas de organización y funciones de la CGR, no están amparadas en normas sustantivas, por ser creadas por ella misma.

El presupuesto asignado a la CGR en los últimos ocho años por S/. 2758 005718,00 para las actividades de control, no han rendido frutos bajo la lógica "Presupuesto para Resultados". La CGR inobserva el artículo 82 de la Carta Magna y su propia Ley, por el cual la misión está orientada a la supervisión del presupuesto.

La investigación fija las bases para implementar la Auditoría Presupuestaria Gubernamental, instrumento potente y eficaz para identificar los actos de corrupción que se dan a través de la ejecución del presupuesto asignado.

\section{REFERENCIAS BIBLIOGRÁFICAS}

Contraloría General de la República del Perú (2014) Resolución de Contraloría No 445-2014-CG de fecha 2014/Octubre/03. Recuperado de: http://www.contraloria.gob.pe/wps/ portal/portalcgrnew/siteweb/inicio/

Constitución Política del Perú (1993). Diario Oficial el Peruano.

Decreto Supremo No 043-2006-PCM (2006). Lineamiento para la elaboración y aprobación del Reglamento de Organización y Funciones - ROF por parte de las entidades de la Administración Pública (publicado el 2006/ Junio/18). Diario Oficial El Peruano.

Decreto Supremo N004-2013-PCM (2013). Politica Nacional de Modernización de la Gestión Pública (publicado el 2013/Enero/09). Diario Oficial El Peruano.

Ley 28411 (2012). Ley General del Sistema Nacional de Presupuesto (publicado el 2012/Diciembre/30). Diario Oficial El Peruano.

Ley 27785 (2002). Ley Orgánica del Sistema Nacional de Control y de la Contraloría General de República (publicado el 2002/Julio/23). Diario Oficial El Peruano.

Lewinsky, S. (2012/Mayo/13). Una paradoja peruana. La República.

North, C. (1993). Instituciones, Cambio Institucional y Desempeño Económico. (2da reimpresión.).Barcelona: Fondo de Cultura Económica.

Rodríguez, V. (2017). Créditos del sistema financiero al sector privado y regulación del mercado de créditos en Perú. Quipukamayoc, 25 (47), 9 - 18. doi: http://dx.doi.org/10.15381/quipu.v25i47.13798 